\title{
The In-Vessel Components of the Experiment WENDELSTEIN 7-X
}

\author{
R. Stadler ${ }^{1}$, A. Vorköper ${ }^{2}$, J. Boscary ${ }^{1}$, A. Cardella ${ }^{1}$, F. Hurd ${ }^{1}$,

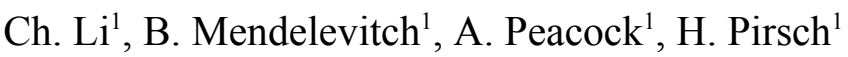 \\ ${ }^{I}$ Max-Planck-Institut für Plasmaphysik, EURATOM Association, Boltzmannstraße2, D-85748 Garching, Germany \\ ${ }^{2}$ Max-Planck-Institut für Plasmaphysik, EURATOM Association, Wendelsteinstraße 1, D- 17491 Greifswald, Germany
}

\begin{abstract}
The in-vessel components of the WENDELSTEIN 7-X stellarator consist of the divertor components and the wall protection with its internal cooling supply. The main components of the open divertor are the vertical and horizontal target plates which form the pumping gap, the cryo-vacuum pumps and the control coils. The divertor volume is closed by graphite shielded baffle-modules and with divertor closures. All these components are designed to be actively water-cooled. For the first commissioning phase planned in 2014, an inertial-cooled test divertor will be installed instead of the actively water-cooled high heat flux divertor. The wall protection consists of graphite-protected heat shields in the higher loaded areas and stainless steel panels in the lower loaded regions. The wall protection cooling circuits are connected through 80 supply-ports via so-called "plug-ins". It is envisaged to protect the diagnostic ports by panel-type port-liners. Special graphite-shielded port liners are used on the diagnostic injector and the neutral beam injector ports. The in-vessel components are mainly manufactured and tested at the Max-Planck-Institute für Plasmaphysik in its Garching workshop. Panels, high heat flux target elements and control coils are delivered by industrial partners. Manufacturing of the KiP ("Komponenten im Plasmagefäß”) is in plan. Delivery of the components will be in time.
\end{abstract}

\section{Keywords}

W7-X; Steady-state operation; Plasma facing component; Divertor; Wall protection; Manufacturing 


\section{Introduction}

The experiment WENDELSTEIN 7-X (W7-X), at present assembled at the Greifswald branch of the Max-Planck-Institut für Plasmaphysik (IPP), is the largest stellarator project to date, with a superconducting magnet system and actively cooled invessel components [1] - referred to as KiP ("Komponenten im Plasmagefäß”). W7-X is designed for steady state operation, with 10 MW input power over a pulse length of up to $30 \mathrm{~min}$ and reaching peak loads up to $20 \mathrm{MW}$ for $10 \mathrm{sec}$. [2]. KiP include the divertor and the wall protection (Fig. 1). For the first commissioning phase in 2014, most KiP will be installed in their final arrangement, but operated without active water cooling. An inertial cooled divertor (TDU) [3] will be installed instead of the high heat flux (HHF) divertor. The cryo vacuum pumps (CVP) will not be installed. This approach was decided to minimize the transition time to steady-state operation at full power with all KiP, including the HHF-divertor, a few years later.

The surface covered by the KiP is approximately 265 $\mathrm{m} 2$, the total weight of the KiP about $33800 \mathrm{~kg}$. The intrinsic challenge is the $3 \mathrm{D}$-shape of the machine and the restricted available space within the vacuum vessel.

\section{Team Approach}

The KiP are prepared by a team located at IPP Garching in close cooperation with a small design team in Greifswald. The components are mainly manufactured at the Garching workshops of IPP. The target elements of the divertor are manufactured by PLANSEE in Austria. The control coils were delivered by BNG and the wall panels are being delivered by MAN-DWE. All incoming inspections of KiP are carried out at Garching.

The KiP-team at IPP comprises 40 persons, distributed over several departments and is structured in a matrix organization.

A production management system (PMS) was developed by FH Reutlingen in close cooperation with IPP for the automation of the manufacturing process and successfully integrated. Data transfer to the project in Greifswald is handled by the common data management system PLM.

\section{Divertor Components}

The divertor consists of ten similar discrete units, situated above and below the helical axis in each of the five-fold field periods.

The divertor components are the target modules, baffle modules, CVP and the control coils. In 2014, the TDU will be installed and replaced later by the HHF divertor. These two components have the same geometry. 


\subsection{HHF Divertor}

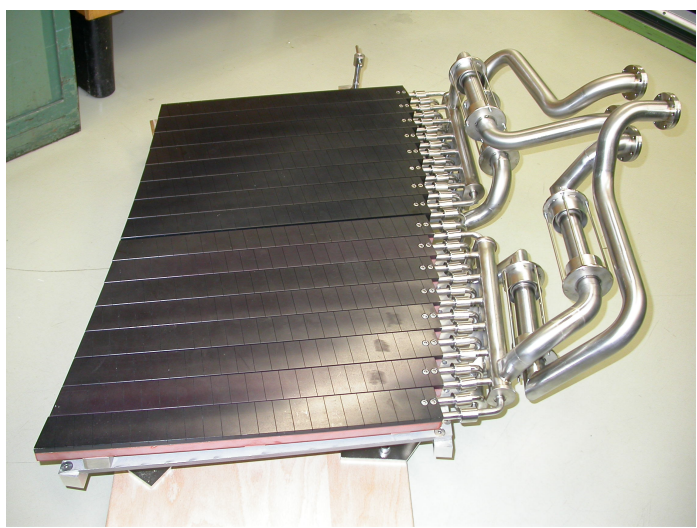

Fig. 2: Full scale prototype HHF target module with dummy target elements. The target elements are water-cooled in parallel from stainless steel manifolds. The inlet/outlet connections to the feeding ports are also shown.

The divertor-units are divided into nine horizontal and three vertical target modules (Fig. 2), which form the pumping gap. The horizontal part is made up of four HHF-target modules, two clamped low heat flux modules and three additional HHF-target modules in a row along the toroidal circumference.

Each HHF target module consists of eight to twelve cooled target elements. The HHF divertor requires the production of about 900 target elements. These elements are designed to withstand a maximum heat load of $10 \mathrm{MW} / \mathrm{m} 2$ and are armoured with Sepcarb $\AA$ NB31 CFC-tiles. The CFC was produced by Snecma Propulsion Solide, France.

In the frame of the pre-series activities, about sixty full-scale TE have been evaluated by HHF tests in the IPP's GLADIS facility and by non-destructive examinations based on the thermography methods in the facilities ARGUS at PLANSEE and SATIR at CEA-Cadarache [4][5].

The low heat flux -units use the same technology as baffle modules.

\subsection{Baffle Modules}

The divertor volume is enclosed by the target and baffle modules. The 170 baffle modules are designed for a maximal heat load of $500 \mathrm{~kW} / \mathrm{m} 2$. They are made of $\mathrm{CuCrZr}$ cooling structures, to which graphite tiles are clamped. The cooling structures are brazed to stainless steel tubes, which are arranged as a cooling meander.

\subsection{Divertor Closures}

The divertor volume, behind target and baffle modules, is closed to achieve an increased pressure in this region, which is required to enhance the efficiency of the CVP. The divertor volume is covered by closure elements, both in poloidal and toroidal direction. The toroidal closure has of the same clamped technology as the baffle modules and low heat flux modules. The poloidal divertor closure, a set of ten stainless steelpanels, is mounted along the baffles.

\subsection{Cryo-Vacuum Pump}

The CVP are located in the divertor volume, behind the horizontal targets. The design of the ten CVPs is based on the layout used in ASDEX Upgrade. Each CVP contain two units, which are shielded by water

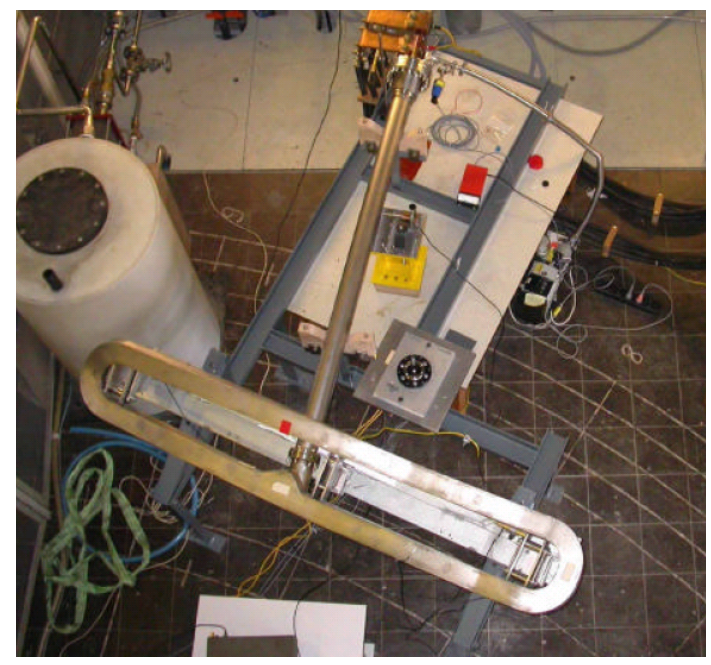

Fig. 3. Control coil after delivery by BNG in test facility at IPP-Garching for incoming inspections. 
cooled chevrons against radiation loads. The CVP is designed for an optimal pumping speed in front of the water chevrons of $75 \mathrm{~m} 3 / \mathrm{s}$.

\subsection{Control Coils}

The ten control coils (Fig. 3), manufactured by BNG, Germany, are also installed behind the targets. The coils are required to compensate symmetry breaking error fields and for sweeping the strike points along the target surface in order to increase lifetime of the target elements possibly.

Each control coil consist of pancake coils (eight hollow $\mathrm{Cu}$-conductors), embedded into a stainless steel casing. Supply of electrical energy and cooling water is performed via current connectors. Each connector passes through the 3T-magnetic field and is designed to cope with the high mechanical forces.

\section{Wall Protection}

The plasma vessel wall is protected by the wall protection elements. On the outboard side close to the plasma surface graphite protected heat shields are installed. The inboard side is covered by stainless steel panels.

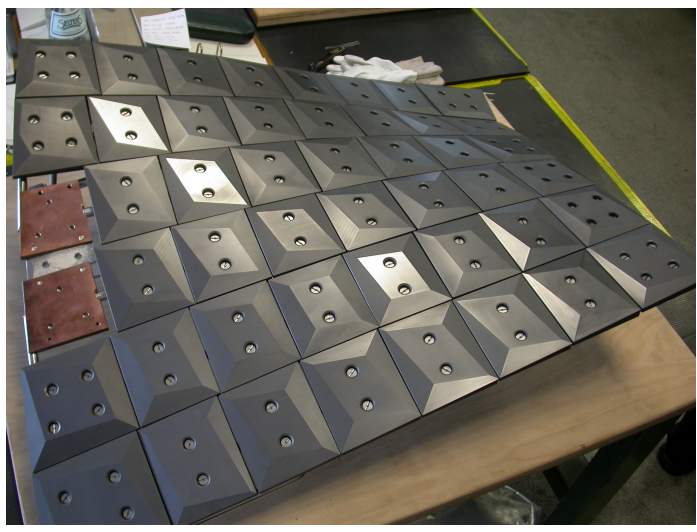

Fig. 4. Heat shield with clamped graphite tiles, two tiles on the left inside are removed to view $\mathrm{CuCrZr}$ plates of the 3D-shaped cooling structure. Every tile is differently machined with facets according to physics specification. Screws are made of TZM.
All wall protection components are designed for active cooling operation.

\subsection{Heat Shields}

The heat shields (Fig. 4) use similar technology to the baffles. The 162 heat shields are designed for a maximal local heat load of up to $300 \mathrm{~kW} / \mathrm{m} 2$. Special beam dump heat shields for the neutral beam injection, the ECRH heating and the diagnostic-injector are integrated within the wall protection.

\subsection{Wall Panels}

The lower thermally loaded area on the outboard region of the plasma vessel as well as the pumping gap area will be covered by approximately 300 steel wall panels (Fig. 5). These panels are designed for a heat load of up to $200 \mathrm{~kW} / \mathrm{m} 2$. The wall panels are manufactured by an industrial team, led by MANDWE, Germany.

For the layout of the panels, the plasma vessel geometry was divided into small cylindrical shaped segments. This allows 1D-bending on the individual wall panel.

A panel is made from a sandwich of two stainless steel sheets. The two sheets are welded together to form a meander of cooling channels. Along the circumference a vacuum tight weld seals the sandwich.

\subsection{Port Liner}

The standard port liners are manufactured with the same sandwich technology as used for the wall panels. 136 standard port liners, with 35 variants are envisaged at present.

\subsection{Graphite protected Port Liner}

In addition to the panel-type port liner, the highly loaded ports for the neutral beam injection (NBI) sources and for the diagnostic injector will be protected by baffle-type liners. The NBI-liners are 
designed for heat loads up to $8 \mathrm{MW} / \mathrm{m} 2$ over $10 \mathrm{sec}$. pulse length.

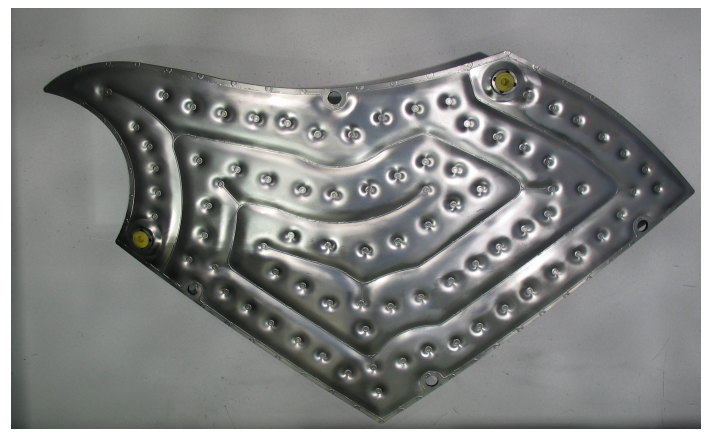

Fig. 5: Wall panel, seen from the backside. The internal cooling structure is clearly visible.

\section{Internal Cooling Supply}

About 1500 components have to be water-cooled within the plasma vessel. A network of pipes with about four $\mathrm{km}$ total length, with 1500 interfaces and 3800 joints, distributes the cooling water between the components. A total of 170 cooling circuits (Fig. 6) with 70 variants connect the components through 80 supply plug-ins. All the wall protection internal supply lines will be installed right from the beginning.

\section{Glow Discharge}

\section{Electrodes}

The ten glow discharge electrodes (Fig. 7) are integrated within the wall panels on the outboard plasma vessel wall. The design allows a current of $3 \mathrm{kA}$ and a voltage of up to $3 \mathrm{kV}$. The glow discharge electrode comprises a graphite dome, thermally connected to a cooled stainless steel base via a ceramic stand-off structure.

\section{Test Facilities used for the KiP-activities}

Several test facilities are being used to perform the incoming inspections of all KiP.

A $3 \mathrm{~m}$ long, $1.2 \mathrm{~m}$ diameter vacuum chamber is operated for leak and out-gassing tests. Hot leak tests at bake-out temperature $\left(160^{\circ} \mathrm{C}\right)$ as well as cold tests at LN2 temperature for the CVP are performed in this facility.

A hydraulic test module is used for temperature distribution analysis and to identify hot spots on the wall panels with an infrared camera. Another hydraulic test facility is operated for pressure drop tests of all $\mathrm{KiP}$

An electrical test facility was installed for testing the control coils at up to 2500 A D.C and 625 A A.C.

The ion-beam facility GLADIS, managed by the Material Research Division (MF), is used for HHFtests $[6][7][8]$.

\section{Conclusion}

The organisation of the fabrication and inspections, using PMS, allows a good work coordination and flexibility, required for such a project. The decision for the manufacturing of additional components, such as the TDU, was managed in an efficient way to set up a plan for the delivery for first commissioning. The quality control with the documentation, related to incoming inspections, either in the industrial partners or in IPP is well managed in PLM to be easily assessed by the project in Greifswald. The present time schedule, based on the experience gained 
throughout the project, show that all components will be available in time for installation until 2014.

Design and production of the KiP at IPP in Garching shows significant progress. The port liners are in different stages of design, several prototypes are being manufactured, some already tested. Extensive HHF testing verified the technology of the standard target elements. 5000 cycles were reached on several elements, one element was even tested to 10000 cycles without failure. $30 \%$ of baffle modules and $60 \%$ of the heat shield structures are ready. Procurement of graphite tiles for both components is running. $60 \%$ of the wall panels were

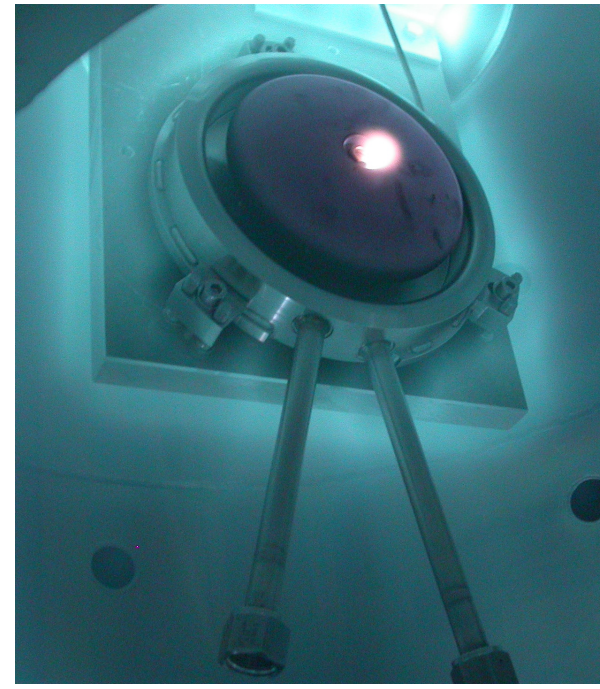

Fig. 7. Prototype glow discharge electrode during test operation in vacuum chamber without cooling. delivered by DWE, 50

additional panel variants are planned. Prototypes of cooling circuits and plug ins were successfully built and tested. Serial production of the cooling circuits has started. $50 \%$ of the parts for the CVP are manufactured, all control coils are ready. The glow discharge electrode manufacturing is nearly complete.

Delivery of the first components to IPP Greifswald has started.

\section{References}

[1] B. Streibl et.al, Manufacturing of the WENDELSTEIN 7-X divertor and wall protection, Fusion Engineering and Design 75$79,(2005)$ 463-468

[2]J. Feist, Systemspezifikation WENDELSTEIN 7-X - Zentrale Maschine, IPP (1999)

[3] A. Peacock et.al., Design and Development of the Test Divertor (TDU) of the Experiment W7-X, IPP, 25th. SOFT (2008)

[4] J. Boscary et.al., Results of the Examinations of the W7-X preseries target elements, Fusion Engineering and Design 82 , (2007) 1634-1638

[5] J. Boscary et.al., Fabrication and Testing Route for the serial Fabrication of W7-X Target Elements, IPP, 25th SOFT (2008)

[6] H. Greuner et.al., High Heat Flux Facility GLADIS: Operational Characteristics and Results of W7-X Pre-Series target Tests, Journal of Nuclear Materials 367-377, (2007) 1444-1448

[7] H. Greuner et.al., High Heat Flux Tests of the WENDELSTEIN 7-X Pre-Series target Elements; Experimental Evaluation of the thermo-mechanical behaviour, Fusion Engineering and Design 82, (2007) 1713-1719

[8] H. Greuner. et.al., Review of the High Heat Flux Testing as an integrated Part of W7-X Divertor Development, IPP, 25th SOFT (2008) 